-Trabalho aprovado por um cos missäo "ad hoc", constitulda por membros da comunidade cientifica local, foi apresentado no I Simpósio Internacional de Estudos Ambientais em Florestas Tropicais Umidas - Forest 90 (Manaus, 7 a 13 de outubro, 1990), com ligeiras alterafóes na forma de expasição do texto.

** Pesquisadora de Malacologia do Instituto Oswaldo Cruz-Fiocruz.

***Pesquisador do Departamento de Ciéncias Biológicas, Escola Nacional de Saude PablicaFiocruz.

\section{O Ensimo da Biologia: Suas Relaçōes com a Experimentação Animal \\ e a Defesa do Meio Ambiente}

\author{
Roxana Valadão** \\ Roberto Milward-de-Andrade ${ }^{* * *}$
}

"Nada, a ti, disso se revela.

Que sabes do homem, do que anela?

Teu ser de aguda, hostil pesquisa,

Sabe do que o homem precisa?"

(Goethe. Fausto)

Referindo-se à polêmica sobre a experimentação animal, este artigo questiona as relaçōes desta com a formação profissional do pesquisador na instituição universitória. As consideraçōes aqui tecidas baseiam-se em dados obtidos através de entrevistas a alunos e professores de cursos de Ciências Biológicas de duas diferentes universidades paulistas. Os dados evidenciam que a utilização de animais não é considerada como um problema ético para a maioria dos entrevistados e que existe um alto indice de desconhecimento das leis, principios e técnicas preconizadas para a experimentação animal. Sugerem, também, que tal situação decorre da orientação classista e do predomínio da tendência tecnicista voltada para a profissionalizaçāo subordinada às demandas do mercado, no ensino universitário.

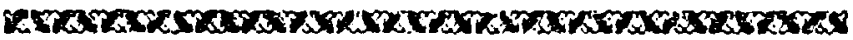

\section{INTRODUÇÃO}

A utilizaçāo de animais no ensino e na pesquisa configura-se, especialmente nos últimos anos, como uma polêmica apresentada com crescente urgência ao meio científico e um problema de natureza ética imposto ao juízo público, pelos movimentos de proteção animal.

Com o objetivo de investigar a visão dominante no ambiente universitário em relação a este tema, foi realizada uma pesquisa através de questionários distribuídos a alunos e professores de cursos de Ciências Biológicas de duas diferentes universidades do estado de São Paulo. Uma parte dos resultados então obtidos 
( $n=94)$ foi apresentada durante a 38: Reuniāo da SBPC (Valadāo et alii, 1986). Posteriormente, a pesquisa foi ampliada, totalizando o índice de 150 entrevistados. O conjunto das respostas aos questionários aplicados foi analisado sob diferentes aspectos e constitui o fundamento das consideraçōes que se seguem.

\section{SOBRE A METODOLOGIA EMPREGADA}

Existe o risco de que o presente artigo seja tomado, simplesmente, como uma discussão teórica em que os autores se orientam segundo uma ótica do bom-senso. Mas, é preciso ressalvar que a escolha da metodologia, instrumentalizada por questionários, teve o propósito de fundamentar a pesquisa aqui tratada, onde importaria discutir, para além das técnicas envolvidas na experimentação animal, o modo como tais técnicas são aplicadas no processo ensino-aprendizagem e os referenciais que nele se evidenciam.

Tratando-se, acima de tudo, de detectar este modo e como ele pode modelar a açấo do futuro profissional e forjar a compreensão que terá do problema, impôs-se ouvir o discurso de quem pratica, ensina e/ou aprende neste processo. Isto porque, tal discurso, evidenciado nas respostas aos questionários, revela o nível de coerência entre a postura teórica e o comportamento prático do pesquisador, além da natureza do conhecimento que fundamenta sua ação concreta, no tocante ao uso dos animais. Nesta perspectiva, a escolha da metodologia extrapola o âmbito das ciências naturais e penetra o universo da cultura humana, tocando, em particular, a questão da universidade brasileira e suas relações com a sociedade em que se insere.

Os dados referem-se ao uso e tratamento dos animais, nāo apenas em seus aspectos técnicos (conhecimento das leis e métodos de manipulação animal), mas também nos aspectos filosóficos e éticos que a questão envolve (visão que o pesquisador tem deste e outros problemas, relacionados ao ensino da Biologia).

Os questionários e entrevistas foram encaminhados, como já mencionado, a um total de 150 professores e alunos de cursos de Ciências Biológicas de duas universidades, o que coloca o problema da representatividade da amostra. Porem, deve-se ressaltar que os dados receberam um tratamento preferencialmente qualitativo, uma vez que os entrevistados foram considerados como capazes de expressar, no nível das idéias e noções aprendidas, a problemática do uso animal na pesquisa científica, por serem eles participantes desta relação.

A leitura de textos sobre a questão da universidade brasileira formeceu subsídios para ligar os elemen- 
tos investigados na pesquisa entẫo realizada, colocando-a no quadro mais geral da educação universitária no Brasil.

\section{AS IMPLICAÇÕES DE ORDEM SOCIAL DO USO DE ANIMAIS}

É inegável que o acirramento da controvérsia a respeito do uso de animais, nos últimos anos, tem trazido inquietação à comunidade científica $(2,4,6$, $7,13,15,21)$. Ainda que exista o risco de que a discussão se torne improfícua, na medida em que os ânimos se exaltam e se acentuam os tons passionais, os movimentos de proteção animal ganham cada vez mais força na Europa e nos Estados Unidos. Um dos representantes destes grupos de proteção, o deputado norte-americano J. Jones, disse: Eu sei que o argumento que se levanta contra nós é o de que a ciência necessita destas experiências. Mas, afinal de contas, se nós queremos fazer estas experiências, deixemos que aqueles que são capazes de maninfestar livremente sua opinião e seu sentimento se submetam eles mesmos... (15). Outros adeptos, em alguns países, recorrem a métodos violentos, como arrombamento de laboratórios para roubo e liberação de animais, ou mesmo atentados a bomba contra cientistas, políticos, autoridades $(5,6,15)$. Na Inglaterra foi criada, recentemente, uma nova cátedra na Universidade de Cambridge, dedicada ao ensino de técnicas cientificas para melhorar as condições de experimentaçăo vividas pelos animais (11). Embora este fato represente um esforço racional de soluçāo para o problema, de um modo muito geral, as posturas emocionais têm sido a tônica desta polêmica.

\section{UMA TENTATIVA DE DELIMITAÇĀO DO PROBLEMA}

Tal situação parece relacionar-se ao desnivel existente entre a magnitude e complexidade do problema evidenciadas na conduta e questionamentos de vários setores da sociedade e a inconsistência e fragilidade das respostas que são efetivamente dadas, expressas na titubeante ação governamental e nas "saídas técnicas" apresentadas por certo número de pesquisadores.

De fato, o sofrimento dos animais, decorrente de sua utilização em laboratório e instituições de ensino e pesquisa, suscita, hoje, questões que vão desde a legitimidade de um progresso que se faz às custas de sua dor, até a reconsideração do verdadeirg lugar que ocupa a espécie humana na cadeia vital. E, também, o motivo da pressăo exercida por certos grupos, 
no sentido de uma revisão dos conceitos básicos sobre a natureza dos direitos e obrigaçōes polf́ticas dos cidadãos e da exigência de iniciativas que regulamentem a intensidade e duração da dor infligida aos animais no curso dos experimentos $(2,4,16)$.

Dentre os argumentos contrapostos a tais questōes, têm importância particular a colocação do caráter subjetivo da dor e a consequaente impossibilidade de sua regulamentação. Isto porque tal colocação, investida de autoridade científica, funciona como gás paralisante neste debate, uma vez que o reconduz ao restrito lugar do discurso objetivo e eminentemente técnico. No entanto, deve-se observar que desta alegada "subjetividade" se valem os pesquisadores, contraditoriamente, para medir a eficácia dos novos analgésicos e anestésicos em seus experimentos. $\mathrm{E}$, sobretudo, é preciso lembrar que a dor confinada ao universo subjetivo não $\varepsilon$, por isto, menos real. Afirmar que

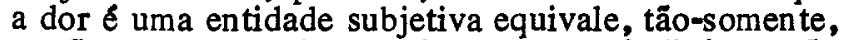
a afirmar que a dor sentida por um indivíduo não pode ser medida. Ora, esta é uma dificuldade técnica. $O$ que importa, porém, é que a natureza do conhecimento em discussão é outra: o que se questiona são os cuştos morais do avanço da ciência.

E possivel admitir que o rumo que toma a discussão sobre o uso de animais decorra de, pelo menos, dois aspectos. Um deles, relaciona-se ao sentido corporativista e elitista da formaçāo profissional na universidade, apontado por inúmeros teóricos de ensino. Por conseguinte, é relevante considerar a eventualidade de que a discussão que suponha uma noção de ética que transcenda os limites do sentimento corporativista apresente-se, no âmbito desta formação, como uma espécie de corpo estranho. $\mathrm{O}$ outro aspecto diz respeito ao que Britt (3) detectou como a relutância dos cientistas em discutir as implicaçōes morais da experimentação animal devido a que, geralmente, sentem-se inseguros em debater assuntos de natureza filosófica, em especial a Ética.

Abordando estes pontos, a pesquisa de Valadão et alii (19) revela que o "respeito aos animais" não é considerado como um problema de natureza ética pela ámpla maioria dos entrevistados, ao contrário do que ocorre com o "respeito ao colega". Também demonstra que Etica é um tema desconhecido por uma parcela significativa dos entrevistados e considerada como uma questão de "bom-senso" por parte dos professores e alunos dos cursos de Ciências Biológicas onde foi realizada a pesquisa.

A adoção do critério de "bom-senso", no entanto, mostra-se inadequada no que se refere ao uso de animais, na medida em que não substitui o conhecimento necessário à sua manipulação, além de levar a uma 
disjunção entre o discurso e a prática, no interior destas instituiçōes. Tal condição pode explicar um fato aparentemente paradoxal revelado nas respostas aos questionários: o aparecimento de acusaçōes de maus- tratos a animais em salas de aula e um alto índice de desconhecimento de leis, prinćpios e técnicas preconizados para o uso destes, enquanto que, surpreendentemente, a maioria dos entrevistados afirma que os animais devem ser tratados com cuidado e respeito.

O critério do "bom-senso", no ensino da Biologia, parece não restringir-se apenas ao caso da ética envolvida no uso de animais. O levantamento efetuado indica que, na formação profissional do biologo, os temas relacionados às interfaces da Biologia com outras áreas de conhecimento são tratados a nível informal. Alguns dados sugerem que a estrutura de certos conceitos como o de vida (que vem a ser o objeto de estudo próprio da Biologia) ocorre de modo assistemático e funda-se, principalmente, em noçōes religiosas. Esta situação leva a uma insatisfação generalizada entre os alunos entrevistados e remete-nos à problemática da dimensão formativa do ensino da Biologia.

As dificuldades levantadas em relação aos cursos de Ciências Biológicas são, entretanto, inseparáveis da crise pela qual passa o ensino numa universidade que, para Fávero (8), Freitag (9), Rezende (12), Subirats (17), Wanderley (20), vem cedendo espaço a uma filosofia pragmatista sob os imperativos de um mercado capitalista em expansão. Este tipo de orientação assume feiçōes próprias nas diversas áreas do saber e, de acordo com Saviani (14), pode implicar prejuízos na formação profissional de alunos de curso superior, onde é necessária a assimilação de todo um conjunto básico de conhecimentos.

\section{COMPONENTES EDUCACIONAIS DO PROBLEMA}

A crise universitária deflagrada na década de 60 e tomada crônica nos anos subseqüentes apresenta-se, para Tedesco (18), como resultado não apenas da massificação do ensino superior, mas, também, da expansão quantitativa dos programas de investigação e ensino. Embora não existam dúvidas quanto à importância da pesquisa técnico-científica no processo de desenvolvimento, não há consenso quando se considera o papel das diversas instituições vinculadas à pesquisa. Saviani (14) chama a atenção para os riscos de se transformar uma atividade de pesquisa num processo de ensino e vice-versa.

Tais riscos estão na origem das distorçōes ocorridas na evolução do ensino universitário, que acabaram 
por deslocar o papel cultural das universidades e neutralizar sua orientação humanística tradicional. Esta "modernização" institucional entranha-se de uma tarefa pedagógica que, como revela a leitura de Gadotti (10), toma-se subsidiária dos interesses dos produtores de serviços num mundo dominado pelo modo industrial de prođução.

Neste contexto, impōe-se admitit, em primeiro lugar, que, no tocante à pesquisa nas diversas áreas das Ciências Naturais, tornamse difícil distinguir o desenvolvimento científico do desenvolvimento econômico-empresarial. Em segundo lugar, este fato altera o quadro em que ocorre o processo ensino-aprendizagem pela introdução de regras que, sendo estranhas ao procedimento científico "puro", sảo, entretanto, desejăveis, guando se trata de relaçōes de prestação de serviços. E possível supor que estas circunstâncias justifiquem a presteza e naturalidade com que pesquisadores assumem posturas em defesa dos interesses de laboratórios e instituições para os quais trabalham, nos confrontos com grupos de proteção animal.

O levantamento dos aspectos da educação universitária, delineados anteriormente, permite uma primeira abordagem ao problema específico da resistência dos pesquisadores às discussões sobre as implicações éticas da experimentação animal.

Este é o caso do sentido elitista da formação universitária, que conduz a um comportamento classista, corroborando a hierarquização de sua estrutura e evidenciando a função da educação como reprodutora de valores e situaçōes vividas na sociedade estratificada em que se insere $(8,9,17,20)$. Esta colocação explicaria alguns dados encontrados na pesquisa realizada. Assim, para a maior parte dos entrevistados $(59,5 \%$ de professores: $P, 69,0 \%$ de alunos da graduação: $A G$ e 71,0\% de alunos da pós-graduação: $A P G$ ), a ética profissional deve ser entendida como um conjunto de normas que trata das relaçōes pessoais entre profissionais; mais de $80 \%$ dos entrevistados consideram que o respeito aos animais não é problema de natureza ética. A identificação da ética como respeito aos colegas é, ainda, sugerida quando se pergunta sobre o tratamento que é efetivamente dispensado aos animais: as respostas evasivas do grupo de $P$ (do tipo "prefiro nảo responder por uma questão de ética") atingem o índice de $54,5 \%$. Como curiosidade, é interessante observar que apenas $4,5 \%$ de $P$ assinalam o respeito ao aluno como problema ético; esta mesma opinião é partilhada por $7,0 \%$ de $A G$ e $6,0 \%$ de $A P G$, o que parece sugerir que os próprios alunos não chegam a perceber a natureza dominadora da relação de que são co-participantes. 
A transformação do ensino universitário, no sentido de uma visão tecnicista que privilegia o pensamento formal, 16gico, "frio" e a orientação profissionalizante subordinada às demandas do mercado, pode também ser identificada nas interaçöes com os animais de estudo, conforme sugerem outros dados, apresentados a seguir.

A maioria dos entrevistados $\varepsilon$ de opiniāo que uma disciplina como "Ética profissional" não deve ser incluída no currículo escolar $(45,5 \%$ de $P ; 29,9 \%$ de $A G$ e $53,2 \%$ de $A P G$ ). Destes, a maior parte justifica que "ética ê uma questão de bom-senso" (70,0\% de $P ; 38,4 \%$ de $A G$ e $55,5 \%$ de $A P G)$, enquanto uma parcela menor alega que o currículo já está sobrecarregado $(20,0 \%$ de $P$ e $23,5 \%$ de $A G)$. O significado desta última alegação pode ser apreendido através da observação de Rezende (12) de que há sempre uma filosofia subjacente às decisōes da polf́tica educacional, que define valores e os hierarquiza para as tomadas de posição relativas às prioridades programáticas (que inclui a programação curricular) e os męios de realizálas. A afirmação de que o estudo de Ética não deve ser incluído porque o currículo já está sobrecarregado equivaleria, nesta perspectiva, à afirmação de que existe muita coisa a estudar e existem assuntos que são prioritários em relação a este. $O$ fato de que uma grande parte do grupo de $A G(31,2 \%)$ desconheça o conteúdo de que trata a Ética, corrobora esta presunção.

A valorização do conhecimento técnico transparece, ainda, quando parte dos entrevistados, nos três grupos, afirma que os animais devem ser tratados de maneira "raçional" $(27,3 \%$ de $P ; 6,6 \%$ de $A G$ e $11,8 \%$ de $A P G)$. E importante esclarecer que a concepção de "racional" está, aqui, identificada à concepção de "cientifico". O equívoco, entretanto, recorrendo mais uma vez a Rezende $(o . c$.$) , está em que se toma como$ postura científica e progressista um comportamento que, na verdade, deriva da noção tecniçista de "modelo", onde os organismos vivos são iden tificados a sistemas cibernéticos, justificando, desta maneira, a propriedade do tratamento racional, objetivo, isento de paixões.

A alta incidência de desconhecimento das leis e princípios que regulamentam o uso de animais $\mathrm{e}$ dos procedimentos e recursos necessários para salvaguardá-los de sofrimento, que aparece nos grupos de $A G$ e $A P G$, está positivamente correlacionada com o desconhecimento de $P$ a respeito destes mesmos problemas. Este fato parece decorrer não apenas da visão tecnicista que transforma seres vivos em "modelos", mas, também, de uma certa atitude favorecida pelo tecnicismo: a sobrecarga dos currículos que, privi- 
legiando as disciplinas técnicas, justifica a restrição das disciplinas humanísticas ao âmbito do informal e acaba por conferir valor informativo à "categoria" do bom-senso.

Descartes inicia seu "Discurso sobre o Método", observando que o bom-senso é a coisa mais bem dividida do mundo, pois cada qual julga estar tão bem-dotado dele que mesmo os mais dificeis de contentar-se em outras coisas, não costumam deseja-lo mais do que possuem.

Ora, o bom-senso é o senso comum e vice-versa. Contudo, na instituição universitária o senso comum se reveste das formas do saber oficial sendo, conseqüentemente, aceito como verdadeiro conhecimento. No caso da afirmação "ética é uma questão de bom-senso" existe, portanto, um tipo de "saber" que é transferido, informalmente, nas interações pessoais do cotidiano universitário. Mas, sendo na realidade um não-saber, este "saber" produz um conhecimento que assume aspectos contraditórios e resulta numa formação profissional deficiente e mal-estruturada.

Para exemplificar o que foi dito, compare-se, a seguir, as respostas dadas a um conjunto de quatro perguntas: $45,4 \%$ de $P, 83,5 \%$ de $A G$ e $70,6 \%$ de $A P G$ afirmam que os animais devem ser tratados com cuidado e respeito; $61,2 \%$ de $A P G$ e $35,3 \%$ de $A G$ acusam maus-tratos a animais em sala de aula, enquanto que esta mesma acusação é negada pela totalidade de $P$. Um alto índice de respostas do tipo "não sei" aparece quando as perguntas referem-se à legislação que regulamenta o tratamento de animais e aos principios e técnicas de seu manejo $(49,5 \%$ de $P, 74,0 \%$ de $A G$ e $53,9 \%$ de $A P G) ; 0$ uso de anestésicos é reconhecido como necessário em vivissecçōes por $53,0 \%$ de $P, 73,5 \%$ de $A G$ e $83,2 \%$ de $A P G$, mas, cerca da metade dos entrevistados não sabe quais anestésicos podem ser usados e mais de $70 \%$ não sabem como proceder na impossibilidade de uso destes.

Um tal quadro configura o que Alves (1) chamou de desintegração do cenário ou colapso das estruturas categoriais que formam o esqueleto arquitetônico de que o sujeito lança mão para organizar sua experiência. E sugestivo que entre alunos de graduaçäo (justamente aqueles que não completaram sua in tegração ao modus vivendi da universidade) se encontre um alto índice de respostas - 53,3\% -, expressando o desejo de que a Etica seja incluída no currículo. Isto pode significar que estes alunos estão sentindo a necessidade de organizarem sua experiência, de serem instruídos de forma explícita e inequívoca a respeito do comportamento que devem ter enquanto profissionais. Sugere, ainda, que a orientação predominantemente técnica que vêm recebendo mostra-se insuficiente para ajudá- 
los a resolver problemas de natureza filosófica com os quais se deparam - o que é perfeitamente compreensível, pois no caso das Ciências Biológicas o objeto de estudo vem a ser, em última instấncia, a vida, que se manifesta e organiza nos seres vivos e se realiza na interaçáo destes entre si e com o ambiente em que vivem. É também preciso lembrar que estes futuros profissionais serão sempre chamados a assumir responsabilidades sociais em situaçōes como a do uso de animais, da agressão ao meio ambiente etc e devem estar preparados para isto.

A insatisfação decorrente da expansão quantitativa dos programas de inspiração técnico-cientf́fica revela-se, além do mais, ao exame das respostas do grupo de $A G$ a outras questões que lhes foram dirigidas. Do total de alunos entrevistados, $54,0 \%$ mostramse insatisfeitos e $62,0 \%$ consideram-se desajustados dentro de seu curso universitário; 77,0\% manifestam frustração em relação às expectativas anteriores ao seu ingresso na universidade. O "conceito de vida" \& apontado por $95,0 \%$ dos entrevistados como um tema interessante e preocupante, mas, acreditam que apenas $34,0 \%$ dos professores teriam fundamentação teórica para discuti-lo; 46,0\% dos alunos afirmam ter uma noção satisfatória a respeito e esta provém da educaçăo religiosa em $50,0 \%$ dos casos, da formação familiar em 33,0\% e da atividade escolar em apenas $17,0 \%$.

Finalmente, alguns fatos chamam a aten ção nesta pesquisa, como, p. ex., aqueles que se reportam aos dados relativos à revelação de maus-tratos a animais em salas de aula, feita por $33,3 \%$ de $A G$ e $62,5 \%$ de $A P G$. Ao traduzir o sofrimento dos animais, revelando os maus-tratos no curso de certos experimentos, estes números tomam objetiva a questão da dor e demonstram que - ainda que de modo indireto - é possivel medir o sofrimento imposto aos animais. Estes dados apontam, alem disto, para uma evidente disparidade entre as posturas destes estudantes e a daqueles pesquisadores que afirmam ser a dor um conceito subjetivo. Esta disparidade pode ser reveladora da deformação produzida por um ensino que conduz, progressivamente, à introjeçāo de uma visão técnico-científica voltada para a orientação profissionalizante. Tal suposiçāo é reforçada, p. ex., pelos números ençontrados em resposta ao problema da inclusão da Etica nos currículos: $53,3 \%$ de $A G, 35,5 \%$ de $A P G$ e $18,8 \%$ de $P$ defendem a inserção desta disciplina no currículo escolar.

Além disto, a preocupação com os gastos acarretados pelo uso de anestésicos nas vivissecçōes de animais, encontrada em $4,4 \%$ de $A G$, sugere a nascente sensibilidade deste segmento ao primado do lucro, o 
que pode constituir uma evidência a mais da profissionalização modelada pela mentalidade empresarial, no interior do ensino universitário.

A maioria dos resultados obtidos está aqui apresentada. $O$ quadro que deles emerge indica que as implicaçōes educacionais subjacentes ao impasse vivido pela experimentação animal resultam de um modelo tecnocrático imposto ao processo de ensino em resposta às necessidades do desen volvimento econômico. Revela, ainda, que esta imposição acaba por introduzir distorçōes na formação profissional e leva ao descompasso entre o nível de capacitação dos indivíduos e as exigências impostas pelo curso dos acontecimentos sociais.

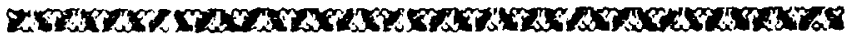

With reference to the controversy regarding animal experimentation, this article questions the relationship with the professional training in universities. The considerations voiced in the paper are based on data gathered from interviews with students and professors of Biological Science courses at two different universities in São Paulo. These data reveal that the use of animals is not seen as an ethical problem by most of the people interviewed and, also, that there exists a high degree of unfamiliarity with the laws, principles and techniques recommended for animal experimentation. It is also suggested that this situation springs from a class orientation and predominance of a technician tendency geared toward professionalization, which in turn is subordinated to market demands, in university teaching.

\section{REFERÊNCIAS BIBLIOGRÁFICAS}

1. ALVES, R. Conversas com quem gosta de ensinar. Cortez Ed. e Ed. Associados. São Paulo, 1986. 88pp.

2. BECK, M. et alii Of $\mathrm{P}$ ain and Progress. Newsweek, 3 (113): 32-6. 1989.

3. BRITT, D. Ethics, ethical committees and animal experimentation. Nature, 5986 (311): 503-6. 1984.

4. COWLEY, G. et alii The price of doing business. Newsweek, 3 (113): 36-7. 1989.

5. DICKSON, D. New row erupts about lab animals. Nature, 5834 (293): 597. 1981.

6. EDITORIA L Protection for lab animals? Nature, 5829 (293): 173-4. 1981.

Cadernos de Saúde Pública, RJ, 6 (4): 444-454, out/dez, 1990 
7. EDITORIA L Do laboratory animals have rights? Nature, 5906 (302): 287. 1983.

8. FÁVERO, M.L.A. Universidade \& Poder. Ed. Achiamé, Rio de Janeiro. 1980. 205pp.

9. FREITAG. B. Escola, Estado e Sociedade. Ed. Moraes, São Paulo. 1980. 142pp.

10. GADOTTI, M. A Educação contra a Educação. Ed. Paz e Terra, Rio de Janeiro. 1984. 172pp.

11. MENDONÇA, C. de Proteção dos animais ganha cátedra em Cambridge, Jornal do Brasil, 1: Caderno: 17, 18/5/1986.

12. REZENDE, A.M. O saber e o poder na Universidade: dominaçăo ou serviço? Cortez Ed. e Ed. Associados, Săo Paulo. 1982. 88pp.

13. ROWSELL, H.C. Animal committees, Nature, 5838 (294): 204. 1981.

14. SA VIANI, D. Ensino público e algumas falas sobre a Universidade. Cortez Ed. e Ed. Associados, São Paulo, 1985. $110 \mathrm{pp}$.

15. SEVCENKO, N. Trégua na guerra contra os animais. Folha de São Paulo, 7: Caderno: 64. 30/3/1986.

16. SHARPE, R. et alii Animals rights and wrongs. Nature, 302 (5910): 649, 1983.

17. SUBIRATS, E. A disfunção da Universidade. Folha de São Paulo, Folhetim: 2-4. 2/4/1986.

18. TEDESCO, J.C. Sociologia da Educaçäo. Cortez Ed. e Ed. Associados, São Paulo. 1983. 103pp.

19. VALADÄO, R, et alii Uso de animais no ensino e pesquisa: aspectos de uma polêmica näo-declarada no ambiente universitário. Ciência e Cultura, 38: 133, 1986.

20. WANDER LEY, L.W.W. O que é Universidade? Ed. Brasiliense, São Paulo. 1985. 83pp.

21. WENZ, C. European convention in sight? Nature, 302 (5906): 284. 1983. 